\title{
Origem do modelo FRBR
}

\author{
Kátia Lúcia Pacheco \\ Cristina Dotta Ortega \\ Universidade Federal de Minas Gerais - UFMG, Brasil
}

\section{REVIEW}

\section{Resumo}

Objetivo.O artigo identifica a gênese dos estudos do modelo conceitual Functional Requirements for Bibliographic Records (FRBR), publicado em 1998, pela International Federation of Library Associations and Institutions (IFLA), com a proposta de desenvolver nova abordagem para o registro bibliográfico.

Método. Recorreu-se à pesquisa bibliográfica para identificar publicações científicas sobre o conceito de modelo e de modelo conceitual para então, a partir de fontes de informação oficiais da IFLA, tratar da gênese do modelo conceitual FRBR, a fim de investigar a trajetória que antecede a publicação do modelo e identificar o debate intelectual em torno de sua elaboração.

Resultado. Constatou-se que o modelo FRBR nasceu com fins eminentemente práticos, pois engendra um conjunto de expectativas em torno da redução de custos da catalogação, indicando um nível mínimo de elementos nos registros bibliográficos que atendam às necessidades dos usuários associadas com os vários tipos de materiais e contextos de uso.

Conclusão. O acúmulo do conhecimento científico, somado à dimensão experiencial trazida e sustentada no modelo, altera os paradigmas da catalogação tradicional, embora o relatório final do modelo não apresente os fundamentos que o sustentam.

\section{Palavras-chave}

FRBR; Requisitos Funcionais para Registros Bibliográficos; Registro bibliográfico

\section{Model FRBR in origin}

\begin{abstract}
Objective. This article aims at identifying the genesis of the studies the conceptual model Functional Requirements for Bibliographic Records (FRBR), published in 1998 by the International Federation of Library Associations and Institutions (IFLA) with the proposal to develop new approach to the bibliographic record.

Method. For this appealed to bibliographical research, primarily the sources of official information IFLA, in order to investigate the trajectory preceding the publication of the model and determine the intellectual debate on its elaboration.

Results. It was found that the FRBR model was born with eminently practical purposes and generates a set of expectations about the reduction of cataloging costs, indicating a minimum level element in bibliographic records that meet the needs of the users associated with the various types of materials and contexts of use.

Conclusions. The accumulation of scientific knowledge coupled with sustained and brought experiential dimension in the model, changes the paradigms of traditional cataloging, but model the final report does not present the foundations that support it.
\end{abstract}

\section{Introdução}

O universo bibliográfico pode ser concebido como um ambiente complexo que engloba várias entidades, em diferentes níveis de agregação. Pode ser visto como uma maneira de abordar o conhecimento registrado, em que todas as unidades documentais são potencialmente recuperáveis. Em certo sentido, o universo bibliográfico é constituído por todos os tipos de objetos, em quaisquer formatos. 
Neste espaço multidimensional nos encontramos entre muitos padrões de organização da informação e nos guiamos por regras específicas respondendo ao "como fazer". Contudo, a esses padrões desenvolvidos e sedimentados no tempo não correspondem teorias que tratem do "por que fazer". As correlações dialéticas implícitas na teoria e na práxis nem sempre são encontradas no exercício da Biblioteconomia.

Nos últimos 17 anos o modelo conceitual, publicado pela International Federation of Library Associations and Institutions. (IFLA), Functional Requirements for Bibliographic Records (FRBR) tem sido fonte de diálogo significativo na comunidade da Biblioteconomia e, também, na Ciência da Computação.

A proposta dos FRBR, de desenvolver nova abordagem para o registro bibliográfico, segundo a IFLA tem dois objetivos "O primeiro é fornecer um quadro estruturado, claramente definido, para relacionar dados especificados em registros bibliográficos às necessidades dos usuários. O segundo objetivo recomenda um nível básico de funcionalidade para registros criados por entidades bibliográficas nacionais." (IFLA, 1998, p. 7).

A estrutura lógica dos FRBR baseou-se numa análise da noção de entidade, utilizada no desenvolvimento de modelo conceitual de sistemas de bases de dados relacionais, o modelo Entidade-Relacionamento (E-R), para explorar o universo bibliográfico e identificar os principais componentes do registro bibliográfico que poderiam ser acordados internacionalmente. A importância histórica do modelo FRBR é reconhecida na medida em que esta foi à primeira análise do universo bibliográfico, formalizada, amplamente divulgada e discutida, utilizando o modelo E-R, embora este modelo não seja a única maneira de análise.

O modelo FRBR, na literatura, é visto como um mote inicial para produzir um novo paradigma de catalogação e construção de bases de dados, ainda que seus conceitos não sejam essencialmente novos, o modelo explicita a estrutura subjacente dos dados bibliográficos. Ao discriminar entidades bibliográficas abstratas e concretas, altera a concepção e organização dos catálogos públicos de acesso em linha (OPAC), permitindo a experimentação de novas estruturas de dados.

As autoras, impulsionadas a compreender o modelo FRBR a partir de algumas dimensões consideradas fundamentais, não muito visíveis na literatura, e que precisam estar articuladas permanentemente ao contexto da pesquisa e da análise, optaram por investigar a trajetória que antecede a publicação do modelo conceitual FRBR. Recorreu-se à pesquisa bibliográfica para identificar publicações científicas sobre o conceito de modelo e de modelo conceitual, para então tratar da gênese do modelo conceitual FRBR, e identificar o debate intelectual em torno de sua elaboração. O mapeamento histórico referente à origem do modelo FRBR foi desenvolvido utilizando-se as fontes de informações oficiais da IFLA. Para tanto, questiona-se: quais foram os pressupostos teóricos nos quais se fundamenta o modelo conceitual FRBR?

\section{Modelo e modelo conceitual}

Para darmos início e nos aproximarmos da questão esboçada na introdução deste artigo, recorremos primeiramente ao conceito de modelo e de modelo conceitual.

Modelos são usados em todos os lugares e em situações variadas, o que admite muitos significados para o termo. Carlyle (2006) apresenta quatro conceitos que ilustram a gama de significados do termo: a representação de alguma coisa; uma descrição esquemática de algum sistema, teoria ou fenômeno; a descrição simplificada de uma entidade ou processo complexo; e um trabalho preliminar ou construção que serve como um plano a partir do qual um produto final deve ser efetuado.

Observa-se nas definições que o modelo incorpora características consideradas importantes para a descrição de um sistema. De modo geral, o propósito de um modelo é esquematizar certa realidade para que ela possa ser analisada. Os modelos podem ser utilizados numa variedade de situações, recebendo denominações próprias, como modelos em escala (usados em arquitetura), modelos matemáticos (usados em muitas das ciências), modelos representacionais (usados na engenharia) e modelos conceituais (usados em projetos de bancos de dados).

Os modelos, segundo a epistemologia Bungeana, são caracterizados por um entendimento conceitual da realidade pela construção de objetos-modelos e de seus modelos teóricos. Para Bunge (1974) os modelos são a verdadeira essência da atividade científica e sua construção torna-se o primeiro passo para a compreensão da realidade, que se dá inicialmente por meio de simplificações e idealizações, isto é, através do que ele denomina objetos-modelo. Porém, os objetos-modelos são de pouca valia para a ciência factual se não forem embutidos em teorias gerais, de onde adquirem seus modelos teóricos ou teorias específicas, pois estes sim podem fornecer explicações e previsões da realidade. 
Para chegar ao conceito da realidade, Bunge (1974) parte das idealizações, na forma da identificação das suas características gerais. A reconstrução conceitual da realidade se inicia, de acordo com o autor, com o objetomodelo ou modelo conceitual de uma coisa ou de um fato e,atribuindo ao mesmo, propriedades possíveis de serem sustentadas por teorias, por meio da identificação de objetos reunidos por apresentarem alguns aspectos semelhantes apesar de se mostrarem claramente distintos. Ao autor importa reconhecer que objetos modelos funcionam como pontes de ligação entre as teorias e a realidade, operando muitas vezes, como instrumentos de validação empírica de uma teoria ou dando origem a novos objetos-modelo e a novas teorias.

Uma realidade específica, ou um objeto, pode ser representado, de acordo com Bunge (1974), de modo mais ou menos esquemático por um modelo, mas "desconfiemos deles, pois podem ser apenas metáforas sugestivas mais do que descrições literais de uma realidade que, sendo mais escondida que aparente não se deixa sempre representar de modo familiar" (BUNGE, 1974, p.27). O autor ressalta que a carência de teorias gerais e abstratas em certas áreas do conhecimento sugere a falta e/ou dificuldade de uma desejável maturidade teórica. Nestas situações a construção de modelos teóricos (ou teorias específicas) começa pelo lado oposto, a partir de algumas hipóteses muito próximas dos dados empíricos originários da observação e da experimentação.

Em suma, podemos perceber, com a ajuda de Mario Bunge (1974), que o fazer científico inicia-se pela elaboração de modelos: aqueles que fazem ou criam alguma coisa podem entendê-la, ao contrário do que acontece com os simples observadores. O processo de modelagem científica fundamenta-se no fato de que teorias gerais, que não se manifestam diretamente sobre a realidade ao aceitarem modelos conceituais, produzem representações de parte da realidade, ou seja, modelos teóricos que proporcionam soluções a situações-problema particulares. Pode-se considerar, então, que um modelo consegue se aproximar da realidade, mas não captá-la em sua totalidade. Os modelos são abordados na medida em que se procuram relações entre as teorias e os dados empíricos.

A abordagem de Cougo (1999) envereda por outro caminho, definindo modelo em sua relação com a análise de sistemas. O autor apresenta uma definição para modelo reforçando a ideia de que o modelo não é o objeto real, mas algo que o representa com grau de maior ou menor adequação. "Modelo é a representação abstrata e simplificada de um sistema real, com a qual se pode explicar ou testar o seu comportamento, em seu todo ou em partes" (COUGO, 1999, p. 7).

O autor ressalta que o importante nesta definição é perceber que através de algum meio, seja uma maquete, uma descrição, um desenho, uma partitura, etc. pode-se antecipar ou substituir a existência de uma realidade qualquer. Através de um elemento semelhante representa-se um objeto desejado e assim pode-se percebê-lo e entendê-lo e fazer algum tipo de operação de controle ou de proposta de significação.

Cougo (1999) chama a atenção para a modelagem de dados, que descreve o desenvolvimento de um sistema de informação e que necessita também de um objeto a ser observado seja ele real ou imaginário. $\mathrm{O}$ autor destaca que, para a obtenção de um modelo a partir de um conjunto de objetos observados, deve-se levar em conta os seguintes pontos: abrangência; nível de detalhamento; tempo para a produção do modelo; e recursos disponíveis. Para a execução da modelagem dos dados é importante observar os seguintes passos: a observação dos objetos; o entendimento dos conceitos; a representação dos objetos; a validação do modelo; a verificação da adequação e de coerência.

Essas duas abordagens (ciência e sistema) parecem convergir para um só ponto, mesmo tendo se manifestado de maneiras diversas, situam o modelo, como designado a representar uma realidade, um objeto real, não literalmente, mas de forma simplificada, possibilitando seu entendimento e tornando-o mensurável, descritível e observável.

Um modelo conceitual, chamado de modelo abstrato no mundo dos sistemas, é convenientemente usado para entendermos uma determinada coisa, para automatizar ou organizar processos que o circundam, compreendendo suas características essenciais e em detalhes.

Codina (1994), por sua vez, acena que um modelo conceitual em sistema de informação documentária expressa seus elementos fundamentais fazendo abstrações dos detalhes particulares das diversas ocorrências dos sistemas reais existentes. Tem por finalidade propiciar uma representação do objeto ou fenômeno permitindo sua compreensão global e, ainda, permitindo entendimento, transmissão e validação de conceitos.

A modelagem conceitual é primordial no projeto de sistemas, visto que é a partir dela que se obtém a estruturação dos conceitos abstraídos de um domínio do mundo real, permitindo sua incorporação em um 
sistema de informação. Tem por objetivo construir uma representação de alta qualidade de um fenômeno selecionado em algum domínio possibilitando o seu reconhecimento.

O modelo conceitual deve apresentar-se no mais alto nível de abstração e sem levar em conta o banco de dados em si, mas a forma como as estruturas serão criadas para armazenar os dados, pois representa a realidade através de uma visão global dos principais dados e relacionamentos, sem se preocupar com as restrições de implementação.

\section{0 modelo conceitual FRBR}

O modelo conceitual FRBR foi elaborado com o objetivo principal de organizar as diversas partes que compõem a estrutura dos registros bibliográficos, recomendando um nível básico de funcionalidade dos registros e relacionando os seus elementos com as necessidades dos usuários, com uso das premissas do modelo E-R de Peter Chen (1976).

Desenvolvido como um meio de análise do registro bibliográfico, então, pode-se dizer que sua estrutura responderá à forma adotada pelo catálogo em um sistema de informação.

Os FRBR definem entidades como os objetos chave de interesse para os usuários de registros bibliográficos, podendo ser concretos ou abstratos. As 10 entidades incluídas no modelo são apresentadas em três grupos distintos:

- Grupo 1 (o que) representa o recurso que está sendo descrito, produto de esforço intelectual ou artístico e possui quatro entidades: Obra, Expressão, Manifestação e Item;

- Grupo 2 (quem) representa os agentes que tem relações com as entidades do Grupo 1, ou seja, entidades responsáveis pelo conteúdo intelectual ou artístico, pela produção física e disseminação ou pela guarda das entidades do Grupo 1: Pessoas e Entidades Coletivas, e;

- Grupo 3 (sobre) abarca os elementos adicionais de representação de tema das obras: Conceito, Objeto, Lugar e Evento.

O modelo FRBR dividiu as entidades em grupos, pois desta forma é possível analisar a entidade para estabelecer as relações das unidades documentais encontradas no universo bibliográfico, como indicado no modelo E-R.

Cada uma das 10 entidades é caracterizada por um número de atributos, ou seja, elementos de informação que servem para identificar e caracterizar a entidade. Os atributos constituem o conteúdo sobre o qual os usuários formulam suas perguntas e interpretam as respostas quando buscam por uma informação. Por exemplo, uma manifestação publicada é identificada, entre outros elementos de informação, por sua data de publicação; uma pessoa é descrita por um nome associado àquela pessoa etc. Assim, cada atributo tem uma função específica ou um conjunto de funções que são essenciais para o catálogo. Smiraglia (2005) observa que cada entidade documentária possui atributos físicos e intelectuais, sendo o atributo físico o suporte dos atributos intelectuais.

O modelo FRBR permite organizar nas bases de dados os atributos das entidades, reunindo-os e interligandoos, através dos relacionamentos bibliográficos das 10 entidades propostas no modelo. O modelo FRBR define os relacionamentos entre as entidades que, segundo a IFLA (1998), "servem como um meio para descrever ligações entre uma entidade e outra, e assim como meio para ajudar o usuário a "navegar" no universo que é representado por uma bibliografia, catálogo ou base de dados bibliográficos" (IFLA, 1998, p. 55). Estes relacionamentos podem ocorrer entre quaisquer entidades, de obra para obra, expressão para expressão, manifestação para manifestação, item para item, expressão para obra, manifestação para item, entre pessoas e entidades coletivas, relacionamentos de assunto, sendo subdivididos em tipos, e subsidiam os usuários em suas tarefas de busca por entidade.

O modelo FRBR identifica originalmente quatro tarefas básicas dos usuários:

- localizar entidades que correspondem aos critérios de busca estabelecidos pelo usuário, ou seja, encontrar uma entidade ou um conjunto de entidades, através de um atributo ou de um relacionamento; 
- identificar uma entidade que permita ao usuário confirmar se encontrou aquilo que procura, distinguindo entre duas ou mais entidades e características similares;

- selecionar uma entidade que atende as necessidades do usuário, isto é escolher uma entidade que atenda as especificações do usuário quanto ao conteúdo, formato físico, etc., ou à rejeição de uma entidade que não atenda suas necessidades; e

- obter acesso à entidade descrita, ou seja, adquirir a entidade desejada seja através de compra, empréstimo, acesso eletrônico remoto. (IFLA, 1998, p. 8).

O resultado do estudo que compõe os seis primeiros capítulos do relatório final do FRBR é o tema do capítulo 7 - Requisitos Básicos para Registros Bibliográficos Nacionais (BLNBR). Os elementos de dados recomendados para o BLNBR são aqueles necessários para ajudar o usuário: a encontrar as obras sobre as quais uma determinada pessoa física ou jurídica é responsável; a encontrar todas as manifestações incorporando expressão de uma determinada obra; encontrar obras sobre um determinado assunto e; encontrar obras de uma mesma série. Os elementos de dados incluem também, campos bibliográficos necessários para identificar uma determinada expressão ou manifestação de uma obra, bem como para selecionar uma obra, expressão ou manifestação e obter uma manifestação. Juntas, essas necessidades representam o nível básico de funcionalidade que o registro bibliográfico deve alcançar.

Os elementos essenciais para a representação do registro bibliográfico indicados no modelo são listados em dois grupos:

- elementos de dados descritivos: área de título e de responsabilidade; área de edição; márea de material específico ou tipo de publicação; área de publicação, distribuição, etc.; área de descrição física; área de série; área de notas e área de número normalizado (ou alternativo) e termo de responsabilidade.

- $\quad$ elementos de organização, ou seja, os pontos de acesso: cabeçalho de nomes; cabeçalho de títulos; cabeçalho de série; cabeçalho de assunto e número de classificação.

\section{FRBR: origem e desenvolvimento}

Os estudos dos FRBR originaram-se no Seminário sobre Registros Bibliográficos promovido pelo Universal Bibliographic Control and International MARC Programme (UBCIM) e pela Divisão para Controle Bibliográfico da IFLA, em Estocolmo, Suécia, no ano de 1990, um pouco antes da 56ª Conferência da IFLA. O Seminário foi organizado com a proposta de examinar a finalidade e a natureza dos registros bibliográficos e as alternativas para atender ao diapasão das necessidades informacionais dos usuários, com custos reduzidos. Durante o Seminário discutiu-se diferentes pontos de vista do registro bibliográfico e suas funções, como resposta à questão central "A catalogação pode ser consideravelmente simplificada?".

É justamente esta questão que permitirá ao grupo de estudo um aprofundamento na questão teórica da atividade de catalogação, pois se pressupõe que a simplificação é decorrente de uma análise altamente complexa.

De acordo com Madison (2005, p. 18), as temáticas que nortearam os trabalhos durante o Seminário foram:

- os custos do processo de catalogação e a simplificação do conteúdo dos registros bibliográficos;

- o aumento do compartilhamento de registros bibliográficos e, consequentemente, a redução de duplicidade da catalogação tanto em nível nacional quanto internacional;

- a explosão da quantidade de material publicado, independentemente do formato em todo o mundo, aumentando assim o interesse no controle bibliográfico universal;

- a crescente conscientização sobre os benefícios de se adaptar as práticas de catalogação e códigos para ambientes eletrônicos que contemplem os sistemas de gerenciamento de bibliotecas online e de grandes sistemas de informação nacionais e internacionais; e 
- o crescente interesse em examinar o papel do universo bibliográfico através dos olhos e necessidades de seus usuários.

A discussão dos participantes, segundo Madison (2005), concentrou-se em determinar o número de elementos de dados descritivos necessários aos registros bibliográficos, atendendo às necessidades dos usuários e para todos os tipos de materiais. Além disso, alguns participantes acreditavam que mais benefícios econômicos poderiam ser provisionados distribuindo o trabalho de criação e compartilhamento de registros bibliográficos, não só às bibliotecas, mas também a outros sistemas bibliográficos como aqueles adotados por editores e livreiros.

Ao final do Seminário deliberou-se que era necessário um acordo internacional amplo sobre as principais funções do registro bibliográfico em resposta às necessidades do usuário e, também, para aumentar e proporcionar maior qualidade ao compartilhamento dos registros bibliográficos. Essas funções deveriam abranger todos os tipos de materiais contemplando o ambiente bibliográfico online.

Conseguinte ao Seminário fez-se o Termo de Referência para o Estudo dos FRBR, elaborado por Tom Delsey (Canadá) e Henriette Avram (Estados Unidos). Madison (2005) assinala que o documento firmou as diretrizes para o desenvolvimento dos trabalhos do grupo de estudo, estabelecendo-se as seguintes premissas:

- determinar a gama de funções do registro bibliográfico, identificando o usuário real e suas necessidades para cada função e conteúdo do registro;

- desenvolver um quadro que identifica e define todas as entidades que são de interesse para o usuário em potencial de registros bibliográficos e os tipos de relações que podem existir entre essas entidades;

- $\quad$ identificar e definir as funções que se espera do registro bibliográfico para cada entidade; e

- selecionar e priorizar os atributos associados às entidades de navegação no universo bibliográfico.

O uso dos termos entidades, atributos e relacionamentos não são comumente utilizados na teoria tradicional da catalogação. O Termo de Referência para o estudo dos FRBR fornece os conceitos destes termos, utilizando como referencial teórico os estudos de: Richard C. Perkinson "Data Analysis: the key to data base design" de 1984; a metodologia desenvolvida por James Martin expressa em seu livro Strategic Data-Planning Methodologies de 1982; Graeme Simsion's Data Modeling Essentials de 1994 e; fundamentos de sistema de banco de dados de Ramez Elmasri e de Shamkant Navanthe de 1989.

Em Nova Déli, na 58ª . Conferência Geral da IFLA, o Comitê Permanente aprovou o Termo de Referência com duas modificações: a adição de assuntos à lista de entidades e a inclusão de um nível básico de funcionalidade para a criação de registros por agências bibliográficas nacionais.

Em agosto de 1991 formou-se oficialmente o grupo de estudos, sob o auspício do Comitê Permanente da Seção de Catalogação da IFLA, composto por voluntários de várias nacionalidades, que até o final dos trabalhos contava com 13 membros de nove países, em sua maioria bibliotecários.

O objetivo do estudo foi definir, em termos claros, as funções desempenhadas pelo registro bibliográfico com relação a vários meios de comunicação, aplicações e necessidades dos usuários. De acordo com Byrum e Madison (2000), o estudo pretendeu cobrir toda a gama de funções para o registro bibliográfico em seu sentido mais amplo, ou seja, um registro que abrange, não só elementos descritivos, mas pontos de acesso (nome, título, assunto, etc.) e notas.

O estudo dos requisitos funcionais para os registros bibliográficos foi visto como tendo implicações teóricas e práticas para a organização da informação. Tillett (1995, p. 44) diz que esse estudo deveria descrever o domínio da teoria da catalogação, isto é, o universo bibliográfico, seus habitantes e as relações entre eles. O estudo é, de fato, uma racionalização de elementos de dados em um registro bibliográfico, no sentido de indicar, para cada elemento de dados a sua "razão de ser", levando a significar, também, uma mudança de paradigma no desenvolvimento de catálogos.

Tillett (1995) completa que as questões que orientaram os aspectos teóricos e práticos do estudo foram: "Como usamos registros bibliográficos em ambientes híbridos? Quais são as funções que esperamos que os registros 
bibliográficos executem? Dada a compreensão dos usos dos registros, quais elementos de dados essenciais ou atributos devem ser refletidos no registro bibliográfico?"

Essas perguntas apontam um caminho para se repensar as possibilidades de uma teoria da catalogação, na medida em que rompe os limites do tecnicismo a fim de fazer circular no debate intelectual questões de fundamentos e princípios da catalogação, que historicamente nortearam a organização da informação. Seria preciso, ainda, investigar o que deve ser um registro bibliográfico, distinguindo entre aspectos essenciais do registro, ou seja, aquilo que o define e os modos contingenciais de produção do mesmo.

Os passos do grupo de estudo foram sintetizados por Tillett (1995) em três etapas:

- formar um consenso entre os consultores e os membros do grupo de estudo sobre as funções do registro bibliográfico;

- desenvolver um modelo do universo bibliográfico que refletisse uma multiplicidade de usuários e usos abarcando todo tipo de material;

- determinar, para cada uma das entidades e relacionamentos identificados, os atributos necessários para realizar as funções estipulados na primeira etapa, indicando o peso para os atributos em gradações de essencial para agregado e se um determinado atributo deve ser submetido à normatização.

Desde o início dos trabalhos, o grupo de estudo determinou que o projeto levaria em conta as necessidades de uma ampla gama de usuários. A decisão desafiadora sobre como realizar uma estratégia focada no usuário foi tratada nas primeiras reuniões. O grupo de estudo, como relata Madison (2005, p. 28), decidiu usar o próprio conhecimento coletivo, tanto pela conveniência quanto pela praticidade, em detrimento da opção óbvia de um estudo de usuário sistematizado, dado o alcance internacional do estudo e o prazo. Os membros do grupo de estudo consideraram que o conhecimento profissional das necessidades do usuário, com base em suas origens e experiências teóricas e práticas, e os tipos de expertise que esperavam atrair para o projeto, atenuariam a necessidade de pesquisas junto aos usuários. Neste sentido, Madison afirma que:

As necessidades de pesquisadores, estudantes, bibliotecários, funcionários de bibliotecas, editoras, fornecedores, varejistas, designers de sistemas e usuários dos serviços de informação, etc., dentro e fora ambientes de bibliotecas tradicionais, foram consideradas e avaliadas dentro do contexto de tarefas como a busca de informações, verificando citações, determinando exibição e funções de recuperação de informação, compras, vendas, gestão de aquisições, catalogação, indexação e resumos, gestão de inventários, circulação, empréstimo entre bibliotecas, preservação, referência, etc. (Madison, 2005, p. 29).

As variadas experiências e interesses teóricos e práticos dos membros do grupo de estudo fizeram com que a sequência de exemplos utilizados para examinar o modelo fosse diversificada e complexa.

Para identificação de atributos do modelo FRBR, o grupo de trabalho baseou-se nas International Standard Bibliographic Descriptions (ISBD), nos Guidelines for Authority and Reference Entries (GARE), nos Guidelines for Subject Autorithy and Reference Entries (GSARE), no Marc Americano (USMARC), nas Categories for the Description of Works of Arts (AITF), na literatura científica disponível na área, e em pareceres dos membros do grupo de trabalho e em pesquisas publicadas.

Madison (2005) relata que, durante os trabalhos do grupo de estudo, as propostas para as entidades mudaram consideravelmente. Em um projeto de 1993, havia a proposta de 6 entidades: superobra, obra, versão, edição, item e partes componentes. Em um projeto de 1995, a proposta para as entidades era: obra, representação, produto, suporte e item. Após comentários e sugestões, detalhados em relatório, de uma equipe de modelagem de dados da Library of Congress, os consultores decidiram fazer extensas revisões para os capítulos sobre entidades, atributos e tarefas do usuário para o projeto de meados de 1995. As entidades foram reduzidas de cinco para quatro: representação foi renomeada expressão com um foco mais claro sobre o conteúdo intelectual ou artístico; produto foi rebatizado de manifestação com a suposição de que ele incorporasse os itens publicados ou não-publicados; suporte foi eliminado uma vez que seus atributos foram incluídos na manifestação; as entidades obra e item não foram alteradas. Com este projeto foram adicionadas novas entidades: pessoa, entidades coletivas, conceito, objeto, evento e lugar (MADISON, 2005). 


\title{
5 Consultoria ao grupo de estudo
}

Três estudiosos, com competências específicas na área de catalogação e reconhecidos internacionalmente, foram selecionados para serem consultores do estudo, objetivando a elaboração do relatório: Elaine Svenonius, Barbara Tillett e Bem Tucker.

Elaine Svenonius, professora do Departamento de Estudos de Informação da Universidade da Califórnia, Los Angeles (UCLA), de acordo com Madison (2005), fez a primeira contribuição para o grupo de estudos dos FRBR sugerindo que fossem considerados quatro grupos de usuários: editores, livreiros, bibliotecários e usuários/pesquisadores. Para Moreno (2011, p. 89), a Teoria Bibliográfica de Svenonius,

\begin{abstract}
Delineia seus fundamentos intelectuais com base num quadro teórico que compreende a organização da informação em um contexto histórico-filosófico e desenvolve os fundamentos relacionados aos objetivos bibliográficos afirmando que o primeiro passo na concepção de um sistema bibliográfico é afirmar seus objetivos. Podemos afirmar que sua teoria é composta de objetivos, entidades, princípios, e linguagens bibliográficas, estas divididas em linguagens de documento e obra, incluindo também a análise das linguagens de assunto em termos de vocabulário, semântica e sintaxe.
\end{abstract}

Svenonius revê a história dos objetivos dos sistemas concebidos para recuperar as informações, posto como um dos pilares do fundamento intelectual da informação, a partir dos estudos de Antonio Panizzi (1850), Charles Ammi Cutter (1876), Julia Pette (1936), Eva Verona, Ranganathan e Seymour Lubetzky (1957) A teoria bibliográfica de Svenonius para Moreno (2011) "é composta de objetivos, entidades, princípios, e linguagens bibliográficas, estas divididas em linguagens de documento e obra, incluindo também a análise das linguagens de assunto em termos de vocabulário, semântica e sintaxe" (Moreno, 2011, p. 89).

Para proporcionar cientificidade a sua teoria bibliográfica, Svenonius (2000) busca subsídio nas ideias de Quine (1980, p. 103). O autor caracteriza as entidades englobadas por uma teoria científica como consistindo dos valores das variáveis, isto é, algo existe somente se esse algo puder ser atribuído a uma variável e formalizado, pois se deve associar à entidade uma quantificação. Svenonius considera que suas variáveis são as entidades que povoam o universo bibliográfico, como por exemplo, as obras, edições, autores e assuntos, pois são objetos primários, abstratos e concretos, admitidos dentro de uma linguagem de descrição bibliográfica como os construtos fundamentais da teoria bibliográfica (Svenonius, 2000, p. 31, 34).

Ao abordar os objetos de descrição, Svenonius (2000) espelha-se na abordagem da questão ontológica de construir um modelo que delineia entidades, atributos e relacionamentos. Como um meio para explicar a teoria, o modelo de construção reflete uma tendência em que uma base de dados é conceituada por um processo de formalização abstrata. A conceituação está sujeita a certas condições. No caso de uma base de dados bibliográfica esta finalidade é codificada nos objetivos adotados pelo sistema. As entidades bibliográficas podem ser definidas conceitual e operacionalmente. Uma definição conceitual é aquela que caracteriza o que deve ser definido em termos de suas propriedades, tais como a capacidade de conhecer ou apreender, e uma definição operacional especifica um conjunto de operações ou passos a serem seguidos para identificar o que está sendo definido. Svenonius (2000) revela que há duas razões para a definição das entidades bibliográficas: a primeira, reforçada por Moreno (2011), "é que, transformando um conceito em uma variável, esta pode ser usada para criação de uma hipótese que, se fundamentada, pode resultar em uma generalização ou uma afirmação teórica" (Moreno, 2011, p. 90) e; a segunda é que este conceito pode ser uniforme, a fim de servir para variados fins em diferentes tipos de atividades.

Svenonius (2000) conclui que a entidade bibliográfica é desenvolvida com base nos aspectos empíricos, e não nos ontológicos. Desse modo, há a falta de precisão e de ambiguidade nas estruturas de determinados tipos de entidades. Algumas destas entidades não podem ser descritas utilizando conceitos tradicionais, por isso elas são limitadas no sentido de que não contam com informações suficientes para listar as suas partes.

A teoria bibliográfica de Svenonius é uma tentativa de relatar princípios, objetivos e técnica em um nível de generalidade e de uma posição conceitual, que facilite a transferência de ideologia e tecnologia além das fronteiras disciplinares, com o objetivo de informar, em última análise, as práticas desenvolvidas para a organização da informação na era eletrônica e avançar nos fundamentos intelectuais da organização da informação. 
Barbara Tillett, chefe da Catalogação da Universidade da Califórnia, possui bastante familiaridade com o modelo E-R, presente em suas pesquisas sobre a estrutura conceitual de catálogos e controle de autoridade. Em seu Ph. D., em 1987, estudou a estrutura conceitual das relações bibliográficas em catalogação. Para Tillett (1988, p. 3) a estrutura conceitual de um catálogo é a que descreve o que deve ser incluído no catálogo, os elementos necessários para descrever essas coisas e a ordem em que eles são exibidos (por exemplo, a ordem prescrita na ISBD), bem como as relações que devem ser feitas entre as coisas incluídas no catálogo.

Durante o estudo dos FRBR, houve questionamentos sobre o porquê da escolha do modelo E-R em detrimento de outras opções de modelagens disponíveis. Tillett defende o modelo e o justifica durante o workshop promovido pela IFLA, em 1994, Havana. Para a autora a modelagem E-R é bem popular em design de banco de dados. Difere de outras abordagens, como os modelos Peter C. Weinstein's Ontology-Base Metadata, ECHO Metadata Model, INDECS, pois apresenta, logo no início, um resumo do esquema abstrato ou conceitual sem determinar um domínio ou universo em particular, sem restrição, ou seja, podendo modelar qualquer universo ou domínio, independentemente de qualquer limitação imposta por tecnologia, técnica de implementação, dispositivo físico ou definição de registro. Considera os dados independentemente do processamento que os transforma, evitando-se assim um viés para qualquer código de catalogação existente. O universo é caracterizado em termos de entidades e entre seus relacionamentos. Em virtude de sua natureza ampla e independente, a modelagem E-R proporciona uma visão unificada dos dados a serem modelados. Uma possível interpretação do modelo E-R aplicada ao catálogo de biblioteca é visualizar registros bibliográficos e registros de controle de autoridade como entidades, elementos de dados dos registros como atributos, e as relações entre os registros e entre os registros e elementos de dados, como relacionamentos. Em tal modelo, as relações poderiam ser vistas de quatro maneiras: relações bibliográficas; relações de nome; relações de assuntos e relações de pontos de acesso.

Tillett reforça que é mais estável e mais simples projetar no modelo E-R do que em um esquema dependente de pressupostos relativos ao que se constitui um registro bibliográfico ou pelo seu armazenamento (Tillett, 1995; Madison, 2005). O modelo E-R, baseado na teoria dos conjuntos e na teoria dos relacionamentos, tem a vantagem de combinar uma técnica de diagrama com uma aproximação semântica à descrição dos dados e à concepção de bases de dados (RíOS HILARIO, 2003, p. 46).

Bem Tucker atuou como consultor do grupo de estudo dos FRBR por um ano. Ele era coordenador do Departamento de Políticas para a Catalogação Descritiva da Library of Congress com larga experiência, tanto prática quanto teórica, em regras internacionais de catalogação em especial, o Anglo-American Cataloguing Rules. Com a saída de Tucker, Tom Delsey, da Biblioteca Nacional do Canadá, docente, administrador, consultor em normas bibliográficas e arquitetura da informação, juntou-se a Svenonius e Tillett. Delsey, segundo Madison (2005), é versado na literatura científica e em aplicações de modelagem E-R, o que influenciou, sobremaneira, a escolha deste modelo.

Uma das qualidades básicas inerentes ao modelo FRBR, de acordo com Tillett (2005), é que ele traz de volta os principais objetivos de um catálogo. A ideia de agrupar versões da obra, ligando trabalhos relacionados, ou reunir todas as obras e manifestações de um autor, não é de fato um novo conceito, pois pode ser rastreada nas idéias de Panizzi, Cutter e Lubetzky, e nos Princípios de Paris (DENTON 2007).

Do que foi exposto até aqui, pode-se dizer que o modelo FRBR representa o culminar de uma longa tradição de catalogação. Com o intuito de deslindar os fundamentos do modelo FRBR, os pontos que o aproxima do âmbito teórico, não explícitos em seu relatório final, valemo-nos do estudo de Denton (2007), sobre a história da catalogação até o modelo FRBR. O autor discorre sobre a catalogação sob o prisma de quatro ideias: o uso de axiomas para explicar o propósito dos catálogos, ou seja, os princípios fundamentais que formam a base de códigos de catalogação; a importância das necessidades dos usuários; a noção abstrata de obra e; a padronização e a internacionalização. Seu propósito latente é apresentar a gradual, embora inevitável, mudança dos catálogos e dos processos de catalogação para o controle bibliográfico universal que, ao se fortalecerem ao longo de décadas, resultaram no modelo FRBR. De acordo com Denton (2007), as quatro ideias começam a ganhar força com a era da catalogação moderna, na segunda metade do século XIX, a partir das 91 Regras de Catalogação de Anthony Panizzi, que foram submetidas a um intenso debate, aprovadas por órgãos governamentais, utilizadas em grandes bibliotecas, envolviam a noção de obra e um olhar atento às necessidades dos usuários. Panizzi não estabeleceu qualquer axioma, mas as noções de obra, padronização e necessidades dos usuários fazem parte do seu legado. 
Charles Ammi Cutter apresentou o primeiro conjunto de axiomas feitos para a catalogação, conforme assinala Denton (2007), com a publicação das Regras para um Catálogo Dicionário, que incluía catalogação de assuntos e de materiais, dando origem a novas concepções de como tratar a informação. Contribuiu de maneira fundamental para o estabelecimento de processos metodológicos na representação de assuntos, proporcionando cientificidade ao procedimento e minimizando a subjetividade do processo de representação temática. A influência de Cutter foi avassaladora e sua visão vanguardista em relação à função dos catálogos foi a principal fonte de códigos de catalogação posteriores. As tarefas dos usuários apresentadas no modelo FRBR, embora mais amplas, pois refletem os avanços da sociedade contemporânea, são, para Denton (2007), descendentes dos princípios apresentados por Cutter.

Denton (2007) apresenta as 5 leis $^{1}$ de Ranganathan, instituídas para a Biblioteconomia em 1931, como exemplos importantes da ideia de axiomas e necessidades dos usuários e salienta que o modelo FRBR, embora de forma não muito explícita, cumpre as leis, na medida em que entendermos por livro, qualquer tipo de obra, de expressão, manifestação ou item. E, ainda se um catálogo adotar o modelo FRBR terá sua coleção mais aberta aos usuários, ampliando as maneiras pelas quais os usuários interagem com ele.

Na sequência do texto, Denton (2007) argumenta que é com Seymour Lubetzky, com seus estudos teóricos sobre a catalogação e a adoção dos Princípios de Paris, primeira normativa de catalogação colaborativa em nível internacional, que os axiomas para a catalogação e a ideia de obra se firmam e se colocam como ponto central na elaboração de normas de catalogação. As 4 ideias apresentadas por Denton (2007) estão presentes nos Princípios de Paris: abordagem axiomática; as necessidades dos usuários; a obra e; a padronização e internacionalização. O modelo FRBR preserva fundamentos presentes na história da catalogação.

É possível perceber alguma preocupação de se assegurar um liame, um trato entre gerações, um compromisso de unidade na diversidade do universo bibliográfico no processo de construção do modelo FRBR. Carlyle (2006) assinala em seus estudos que ao longo da história das bibliotecas tem-se utilizado diferentes modelos para representar o universo bibliográfico, embora não formalizados, tais como: a) modelo de uma entidade quando os catálogos eram formados por listas simples de itens, em forma de inventário, em que a única entidade reconhecida era o item ou a cópia, ou seja, a única entidade a ser descrita é o documento físico; b) modelo de duas entidades quando os catálogos começaram a funcionar como sistemas de recuperação. As entidades reconhecidas e descritas nos catálogos são as edições e o item; c) modelo de três entidades quando os catálogos usam o título uniforme de forma consistente como forma de arquivamento e representando a obra, ou seja, as entidades reconhecidas são obra, edições e cópias; d) modelo de quatro entidades quando se distingue a entidade expressão, como postulado no modelo FRBR que reconhece as entidades obra, expressão, manifestação e item.

Após quatro anos de estudos, os consultores do Grupo de Estudo elaboram um relatório que, em 1996, durante seis meses, foi submetido a uma revisão mundial por especialistas da área de Biblioteconomia. O processo de submissão provocou quarenta respostas de dezesseis países. Byrum e Madison (2000) relatam que a maioria dos comentários envolveu aspectos sobre a organização do relatório, a definição de termos, a metodologia e as conclusões relativas aos requisitos para tipos específicos de materiais e solicitações de mais exemplos no texto, a fim de esclarecer várias definições e conceitos. Os comentários foram muito úteis para o grupo de estudo avaliar e produzir uma série de melhorias no modelo FRBR, pois se observou que o escopo e o propósito do modelo não foram bem entendidos por todos.

Depois de rodadas de audiências em todo o mundo, críticas e comentários individuais e de organizações, o relatório preliminar foi apresentado ao Comitê Permanente da Seção de Catalogação da IFLA, em 1997, na Conferência Geral da instituição realizada em Copenhague. O Comitê aprovou o relatório final em sua $63^{a}$ reunião de 5 de setembro de 1997. O Relatório final do FRBR foi publicado no início de 1998.

\section{Considerações finais}

O texto seminal do modelo conceitual FRBR, publicado pela IFLA em 1998, oferece uma nova perspectiva para a organização da informação. É um modelo conceitual formalizado para o universo bibliográfico, com potencial para formar a base conceitual de uma nova geração de bases de dados bibliográficas.

\footnotetext{
${ }^{1} 5$ Leis de Ranganathan: 1 - Os livros são para serem usados; 2 - Todo o livro tem o seu leitor; 3 - Todo o leitor tem o seu livro; 4 - Poupe o tempo do leitor; 5 - Uma biblioteca é um organismo em crescimento.
} 
Podemos dizer que o modelo FRBR fornece um novo olhar sobre o universo bibliográfico, descrevendo-o tal como o conhecemos hoje e oferecendo possibilidades de mudanças do paradigma de desenvolvimento de catálogos, reformular os princípios da catalogação, já historicamente conhecidos, às possibilidades oferecidas pelo modelo E-R.

Os FRBR podem trazer benefícios, em primeira instância, aos criadores de bases de dados bibliográficas que, com o enfoque sistêmico do modelo $E-R$, discriminam as entidades do plano abstrato para o concreto e, ao relacioná-las, organizam as entidades por semelhanças, no entanto, de forma mais abrangente do que as opções de um catálogo tradicional, eletrônico ou não. Em um segundo momento, os FRBR podem trazer benefícios para os usuários que acessam as entidades do catálogo podendo navegar com mais certeza no universo bibliográfico.

Como vimos no decorrer do artigo, o estudo do modelo conceitual FRBR nasceu, de fato, com fins eminentemente práticos, para controle bibliográfico, a fim de reduzir custos e aumentar o compartilhamento de dados em nível nacional e internacional. Estudar os requisitos mínimos funcionais de registros bibliográficos parecia ser uma ferramenta indispensável para o controle bibliográfico.

Os processos de elaboração do modelo FRBR obedeceram a uma dinâmica específica, determinada pelo termo de referência. O modelo FRBR, ainda que revestido de um conceito substancialmente mais amplo do que os conferidos à catalogação tradicional, estruturado em bases próprias, diferentemente das regras e formatos bibliográficos, não apresenta o embasamento da teoria de catalogação em que se fundamenta.

Se é necessário repensar a catalogação a partir de entidades, atributos e relacionamentos, como proposto no modelo FRBR, para então construir uma teoria da catalogação, não se pode mais esquivar de discutir os pressupostos teóricos que historicamente levaram à formulação deste modelo.

Compreender em profundidade os próprios pressupostos do modelo FRBR, cujo compromisso já está de antemão construído, dada a dualidade de sua natureza (é novo e original, e ao mesmo tempo se baseia numa tradição firmemente estabelecida), é ainda desafiador, pela falta de publicação dos debates teóricos ocorridos durante o estudo. O relatório final do modelo não apresenta os fundamentos que o sustentam, do que supomos que o relatório não foi produzido com tal pretensão.

Com base no exposto, entendemos que não cabe contestar a validade do modelo conceitual FRBR para o desenvolvimento da Biblioteconomia. O acúmulo do conhecimento científico, somado à dimensão experiencial trazida e sustentada no modelo, não há dúvida, ilumina aspectos da catalogação, possibilitando alterar inevitável e profundamente até os modos de ensinar a catalogação.

\section{Referências}

BUNGE, M. Teoria e realidade. São Paulo: Perspectiva, 1974. 243p.

BYRUM, John D., MADISON. Reflections on the goals, concepts and recommendationsof the IFLA study on Functional Requirements of Bibliographic Records. In: FRBR Seminar, 2000, Florence. Conference..., Edited by Vani Bertini. Florence: AIB, 2000. Disponível em: http://www. aib.it/aib/sezioni/toscana/conf/frbr/byrmadis. htm. Acesso em: janeiro de 2015.

CARLYLE, Allyson. Understanding FRBR as a conceptual model: FRBR and the bibliographic universe. Library Resources \& Technical Services, v. 50, n. 4, p. 264-273, 2006.

CHEN, Peter, The Entity-Relationship model: toward a unified view of data. ACM Transactions on Database Systems, v. 1, no. 1, p. 9-36, 1976.

CODINA, Luis. Modelo conceptual de un sistema de informacion documental. $\underline{\text { Revista española de documentación }}$ científica, v. 17, n.4, p. 440-449, 1994.

COUGO, Paulo. Modelagem conceitual e projeto de banco de dados. Campus: Rio de Janeiro, 1999. 296 p.

DENTON, William. FRBR and the history of cataloging. In: understanding FRBR: what it is and how it will affect our retrieval tools. Ed. Arlene G. Taylor. Westport, Connecticut: Libraries Unlimited, 2007, p. 35-57.

IFLA. Study Group on the Functional Requirements for Bibliographic Records. Functional Requirements for Bibliographic Records: final report. München: K. G. Saur, 1998. Disponível em: http://www.ifla.org/files/assets/cataloguing/frbr/frbr 2008.pdf. Acesso em: 16 jul. 2015. 
MADISON, Olivia M. A. The origins of the IFLA sutudy on Functional Requirements for Bibliographic Records. In: Le Bœuf, Patrick (ed.). Functional Requirements for Bibliographic Records (FRBR): Hype, or Cure-All? Binghamton, NY: Haworth Press, 2005, p. 15-37.

MORENO, Fernanda P. Em busca dos objetivos bibliográficos: um estudo sobre catálogos. 2011. 162fls. Tese (Doutorado em Ciência da Informação). Universidade de Brasília, 2011.

QUINE, W. V. From a Logical Point of View: nine logico-philosophical essays. 2 ed. Cambridge : Harvard University Press, 1980. $200 \mathrm{p}$.

RíOS HILARIO, A. B. Nuevos horizontes en el análisis de los registros y la normativa bibliográfica. Gijón: Trea, 2003. 165 p.

SMIRAGLIA, Richard P. Instantiation: toward a theory. In: Data, information, and knowledge in a networked world; Canadian Association for Information Science Annual Conference, 2005, London, Proceedings... Ontario: ed. Liwen Vaughan, 2005.

SVENONIUS, E. The intellectual foundation of information organization. Cambrigde, MA: MIT Press, 2000. $280 \mathrm{p}$.

TILLETT, Barbara. Bibliographic relationships in library catalogues. International Cataloguing and Bibliographic Control, v.17, n.1, p.3-6, Jan./March, 1988

TILLETT, Barbara. Theoretical and practical foundations. In: IFLA study on Functional Requirements for Bibliographic Records. International Cataloguing and Bibliographic Control IFLA. UBCIM, London, v. 24, n. 3, p. 43-44, 1995. 


\section{Dados dos autores}

\section{Kátia Lúcia Pacheco}

Graduada em Biblioteconomia, especialista em Organização da Informação em Contextos Digitais e mestre em Ciência da Informação pela Escola de Ciência da Informação da Universidade Federal de Minas Gerais (ECI/UFMG). É doutoranda do Programa de Pós-Graduação da ECI/UFMG. Atua como bibliotecária/documentalista na Escola de Música da UFMG. Atuou como Professora Substituta na ECI/UFMG e como tutora do I Curso de Aperfeiçoamento em Educação a Distância do Sistema CAPES/UAB/UFMG. Tem experiência na área de organização e uso da informação, com ênfase em processo de representação descritiva e temática da informação. Seu escopo de estudos abrange: sistemas de classificação, representação descritiva e temática, documentos musicais, FRBR, título uniforme, sistemas de recuperação da informação. Tem interesse em estudos de inventários de acervos e administração pública.

katialp@ufmg.br

\section{Crstina Dotta Ortega}

Graduada em Biblioteconomia, mestre em Ciência da Informação e Documentação e doutora em Ciência da Informação pela Escola de Comunicação e Artes, da Universidade de São Paulo (ECA/USP). Experiência profissional em produção e gestão de bases de dados e de tesauros orientados aos contextos institucionais. Atualmente é professora Adjunta na Escola de Ciências da Informação da Universidade Federal de Minas Gerais (ECI/UFMG), atuando no curso de graduação em Biblioteconomia (orientação de bolsas de iniciação científica e da atividade optativa de elaboração de monografias) e no Programa de Pós-Graduação em Ciência da Informação (orientação em nível de mestrado e doutorado). Pós-doutorado em andamento na Universidade Federal Fluminense (UFF) sobre o tema da mediação em Ciência da Informação. Desenvolve atividades de pesquisa e de ensino voltadas aos aspectos teóricos, metodológicos e históricos da organização da informação em abordagem bibliográfica, e em sua relação com as abordagens museológica e arquivística, no que tange às atividades de ordenação de documentos, produção e gestão de registros de bases de dados e produção e gestão de linguagens documentárias. Fundamenta a organização da informação como parte do conjunto das ações de mediação documentária que promovem a transformação do objeto em documento, sob aportes dos estudos da linguagem. Em termos histórico-conceituais do campo, adota as perspectivas da Bibliografia, da Biblioteconomia, da Documentação e da Ciência da Informação, considerando as relações e dissensões entre os mesmos e, de outro modo, os aspectos da organização da informação em abordagem museológica e arquivística.

ortega@eci.ufmg.br

Recibido - Received: 2015-08-24

Aceitado - Accepted: 2015-10-19

\section{(cc) EY}

This work is licensed under a Creative Commons Attribution 4.0

United States License.

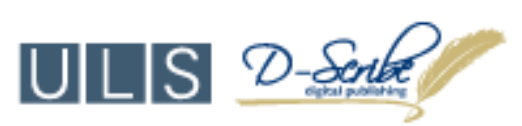

This journal is published by the University Library System of the University of Pittsburgh as part of its D-Scribe Digital Publishing Program and is cosponsored by the University of Pittsburgh Press. 